\title{
Intraoperative ultrasonography of liver, bile ducts and pancreas
}

\begin{abstract}
The use of intraoperative ultrasonography (IOUS) to evaluate liver, bile ducts and pancreatic disease, as compared to the results of preoperative ultrasonography and CT, is discussed. Forty-two patients who underwent abdominal surgery for suspected hepatobiliary and/or pancreatic disease were studied. The intraoperative study was carried out with a portable apparatus (Aloka 500, Japan), using $5.0 \mathrm{MHz}$ and $7.5 \mathrm{MHz}$ linear sterile transducers. The main indications for IOUS were the search for and/or evaluation of primary hepatic masses, hepatic abscesses or metastases, obstructive jaundice, or neuroendocrine tumors. In 15 cases (38.5 percent) from the hepatobiliary group and in 7 cases ( 58.3 percent) from the pancreatic group, a difference between preoperative and intraoperative findings was observed. The main difference was observed in relation to the number and size of hepatic and pancreatic lesions. The relationship between the lesions and the vascular structures was evaluated through IOUS. The method was also used to guide surgical procedures such as biopsies, the alcoholization of nodules, and the drainage of abscesses. IOUS plays an important role in detecting small hepatic and pancreatic nodules, in the assessment of anatomical relationships between the lesions and the vascular structures, and in the performance of interventionist procedures.
\end{abstract}

UNITERMS: Diagnosis. Image/classification. Ultrasonography/methods. Intraoperative period. Liver/Ultrasonography. Pancreas/ Ultrasonography. Bile ducts/Ultrasonography.

\section{INTRODUCTION}

$\mathrm{T}$ The first efforts to use intraoperative ultrasonography (IOUS) took place in 1961. At that time, ultrasonography was an unidimensional procedure, used in neurosurgery. ${ }^{1}$ In the same year, Schlegel et al. ${ }^{2}$ used the method for localizing kidney stones. Hayashi et al. ${ }^{3}$ reported cases of gallbladder calculi, in which the diagnosis was achieved by means of a special laparoscope with an attached transducer.

\section{Adress for correspondence: Giovanni Guido Cerri \\ Rua Jaguaribe, 567, Vila Buarque \\ São Paulo/SP - Brasil - CEP 01224-001}

In Britain in 1963, Knight and $\mathrm{Newel}^{4}$ reported the use of IOUS in the exploration of the common duct, during cholecystectomy for gallstones. ${ }^{4}$ In 1965, Eiseman et al. ${ }^{5}$ carried out 93 intraoperative ultrasonographic explorations for bile duct evaluation. They first used a normal transducer, which was further improved by significantly reducing its dimensions, in order to insert it into the common duct. In this study, they found 18 common duct calculi. Two false-positive and two false-negative cases were observed.

Nevertheless, IOUS did not achieve the desired results. Thus, the equipment was not improved, and further research for the development of the technique was not carried out. Only in 1978, with the appearance of temporal (B mode) apparatus, did some groups start to perfect the method. ${ }^{6}$ The pioneers in hepatobiliary and pancreatic surgery were Sigel et al. ${ }^{7}$ in the United 
States, Lane and Coupland ${ }^{8}$ in Australia, and Makuuchi ${ }^{9}$ in Japan.

More recently, IOUS has been used as a complementary technique during a number of surgical procedures, such as hepatobiliary and pancreatic operations. This technique has been largely used in hepatic operations, since the liver is a bulky organ and its deeper areas are not within the reach of direct surgical exploration. The evaluation of the hepatic vasculature is of great interest, since IOUS allows its observation without artifacts, differenting from most vascular radiologic examinations, which require complex and expensive devices, not always available in regular operating room facilities.

The role of IOUS in the study of liver conditions is to detect and establish the extent of lesions, particularly when they are minute and deeply located. This role is of further importance when one remembers that complementary intraoperative hepatic assessments, apart from inspection and palpation, are practically nonexistent or inaccurate, as are for example cholangiography and portography. The evaluation of lesions, and their relationship to vascular structures, is decisive for surgical strategy. ${ }^{6.10} 111$

The pancreas is a relatively small organ, fairly accessible to palpation. It is crossed by the main pancreatic duct and the common bile duct. Opacification and

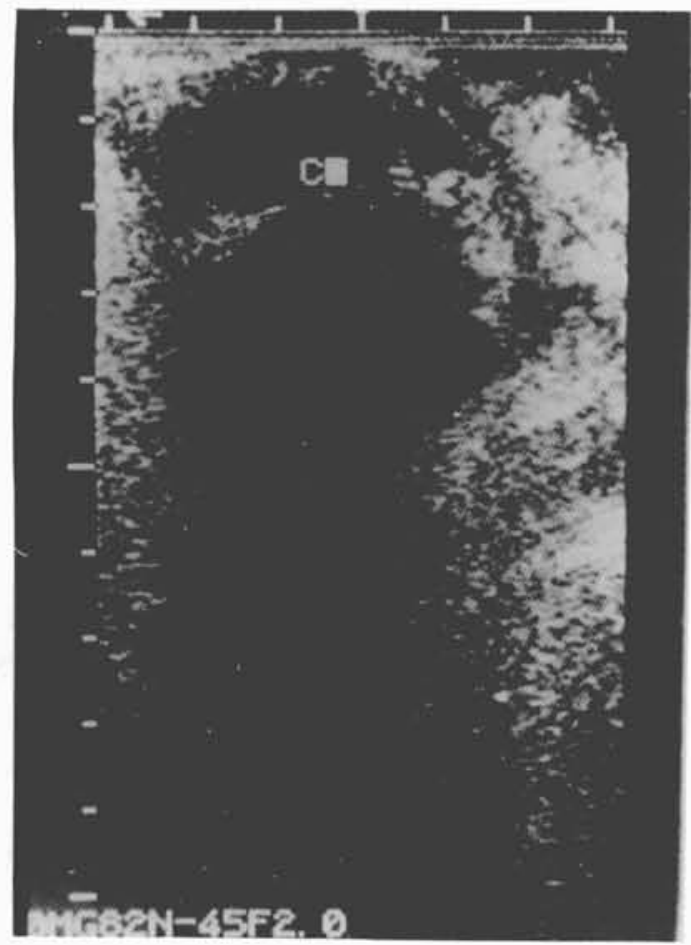

Choledochal cyst with calculi

Figure 1 - Great dilation of choledochus with multiple calculi. portography provide some information (usually indirect) on the existence of disease in these structures. As a result, ultrasonography has played an important role in providing data on pancreatic parenchima. In addition, it can be a guide to the catheterization of pancreatic duct when necessary, and is helpful in evaluating vascular structures as well. ${ }^{6,12}$

Intraoperative evaluation has played a complementary role, to the techniques already used by surgeons for the study of bile ducts: namely, cholangiography and choledochoscopy. ${ }^{6}$

Enthusiasm for IOUS is explained by its ability to provide information on organ parenchima and vasculature. Furthermore, the technique is non-invasive, low-cost, fast and easily executed, with the advantage of not prolonging operative time significantly. ${ }^{13.14}$ IOUS has also the advantage of surpassing the limitations of percutaneous techniques by eliminating the interference of the abdominal wall, ribs and the presence of air in the bowel. Due to the direct contact between the transducer and the organ under examination, the method allows the use of a high-frequency beam, which also leads to better resolution and better quality images. This explains the results of various studies, which have shown a higher sensitivity in the detection of small hepatic and pancreatic tumors by IOUS when compared to preoperative ultrasonography, CT, and angiography. ${ }^{15}$

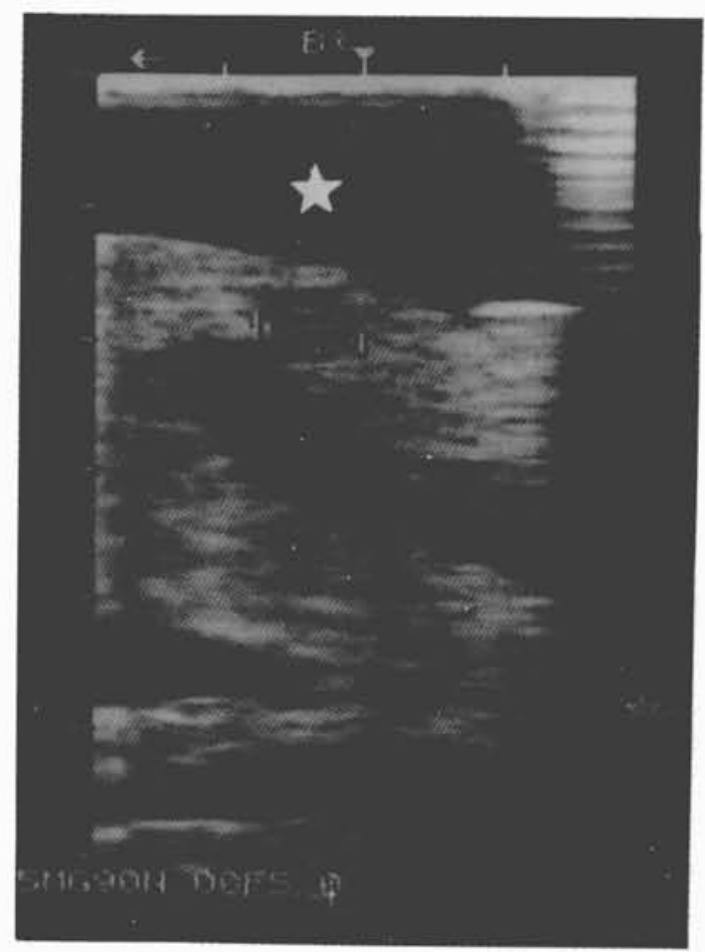

Insulinoma

Figure 2 - The nodule is better visualized by interposing a surgical glove filled with saline solution. (") 
Table 1

Comparison between pre and postoperative findings (liver and bile duct.)

\begin{tabular}{|c|c|c|}
\hline Patient & Preoperative US/CT & IOUS \\
\hline 1. & Diffuse hepatic nodules & Same findings \\
\hline 2. & Choledochal cyst with calculi & Same findings \\
\hline 3. & Hepatic nodule in right lobe (segment VII) & $\begin{array}{l}\text { Two nodules, one in right lobe (segment VII), } \\
\text { the other in left lobe (segment II) }\end{array}$ \\
\hline 4. & Normal liver & Same findings \\
\hline 5. & Choledochal dilation & Same findings \\
\hline 6. & Normal liver & Same findings \\
\hline 7. & Normal liver & Same findings \\
\hline 8. & Normal liver & Same findings \\
\hline 9. & Mass in gallbladder & $\begin{array}{l}\text { Mass in gallbladder, hilar lymphadenopathy, } \\
\text { dilation of intrahepatic bile duct. }\end{array}$ \\
\hline 10. & $\begin{array}{l}\text { Right hepatic lobe mass, } \\
\text { with invasion of left lobe (segment IV) }\end{array}$ & $\begin{array}{l}\text { Right hepatic lobe mass with no invasion of left lobe; } \\
\text { deviation in middle hepatic vein }\end{array}$ \\
\hline 11. & 4 solid nodules in the right hepatic lobe & Same findings, plus one $1 \mathrm{~cm}$ solitary nodule in segment VII. \\
\hline 12. & Normal liver & Same findings \\
\hline 13. & Hepatic abscesses & Hepatic metastases \\
\hline 14. & Normal liver & Same findings \\
\hline 15. & Chronic hepatic disease & Same findings \\
\hline 16. & Hepatic nodule & Same findings \\
\hline 17. & Hepatic abscesses & Same findings \\
\hline 18. & Hepatic Abscesses & Same findings \\
\hline 19. & Hepatic metastatic nodules & Same findings \\
\hline 20. & $\begin{array}{l}\text { Mass in right and left hepatic lobes } \\
\text { (segments V and IV) + Chronic Calculus } \\
\text { Cholecystitis }\end{array}$ & $\begin{array}{l}\text { Liver: same preoperative findings. } \\
\text { Bile duct: Cholesterolosis }\end{array}$ \\
\hline 21. & Normal liver & Same findings \\
\hline 22. & Normal liver & Chronic liver disease \\
\hline 23. & Normal liver & Same findings \\
\hline 24. & Fatty liver & Several small hepatic cysts \\
\hline 25 & Three hepatic nodules & Same findings \\
\hline 26. & Normal liver & Normal liver. Hilar lymphadenophaty \\
\hline 27. & Normal liver & Same findings \\
\hline 28. & Nodule in right hepatic lobe (segment VII) & Two nodules in segment VII \\
\hline 28. & Nodule in right hepatic lobe (segment VII) & Two nodules in segment VII \\
\hline 29. & Left hepatic lobe Mass & $\begin{array}{l}\text { Left hepatic lobe mass. Mass in segment VII, } \\
\text { close to right hepatic vein opening. }\end{array}$ \\
\hline 30. & $\begin{array}{l}\text { Left intrahepatic bile duct dilation } \\
\text { with junctional amputation }\end{array}$ & Same findings \\
\hline 31. & Complex lesion in left hepatic lobe & Same findings \\
\hline 32. & Normal liver & Same findings \\
\hline 33. & Papillary tumor & Papillary tumor. Bile duct dilation. \\
\hline 34. & Normal liver & Same findings \\
\hline 35. & Normal liver & Same findings \\
\hline 36. & Normal liver & Same findings \\
\hline 37. & $\begin{array}{l}\text { Chronic liver disease. Solid nodule } \\
\text { in segment VII. Cyst in segment VII }\end{array}$ & $\begin{array}{l}\text { Same findings, plus } 3 \text { more small solid } \\
\text { nodules in left lobe }\end{array}$ \\
\hline 38. & Chronic liver disease. Left lobe mass & $\begin{array}{l}\text { Chronic liver disease. Left lobe mass. } \\
\text { Solid nodule in right lobe (segment VI) }\end{array}$ \\
\hline 39. & Left hepatic lobe mass & Same findings \\
\hline
\end{tabular}




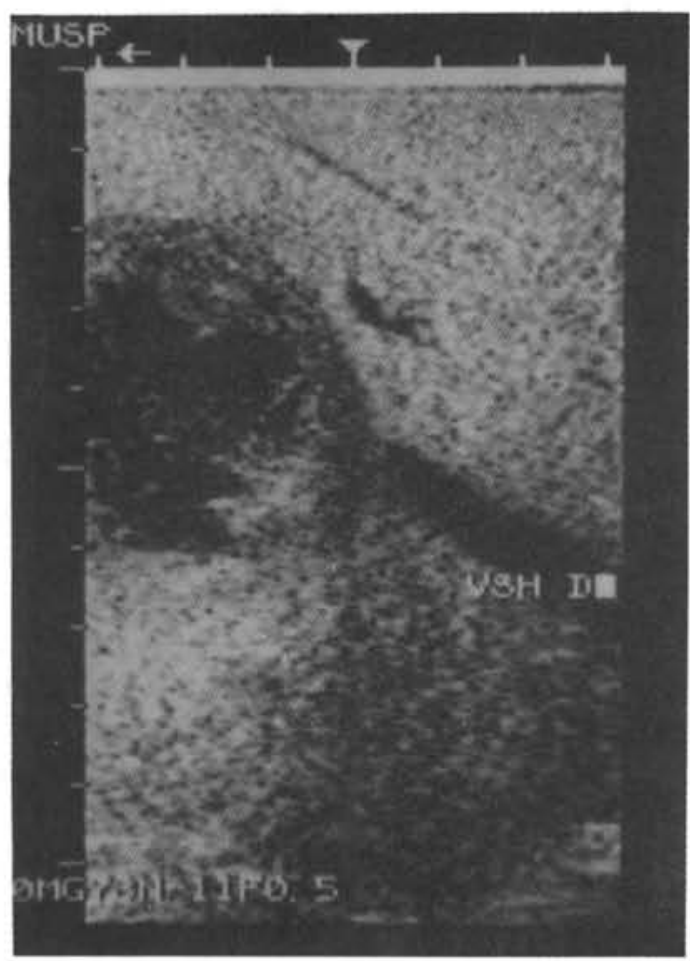

Hepatic metastases of carcinoma of the colon Figure 3 - Solid nodule with necrotic center, deviating right suprahepatic vein.

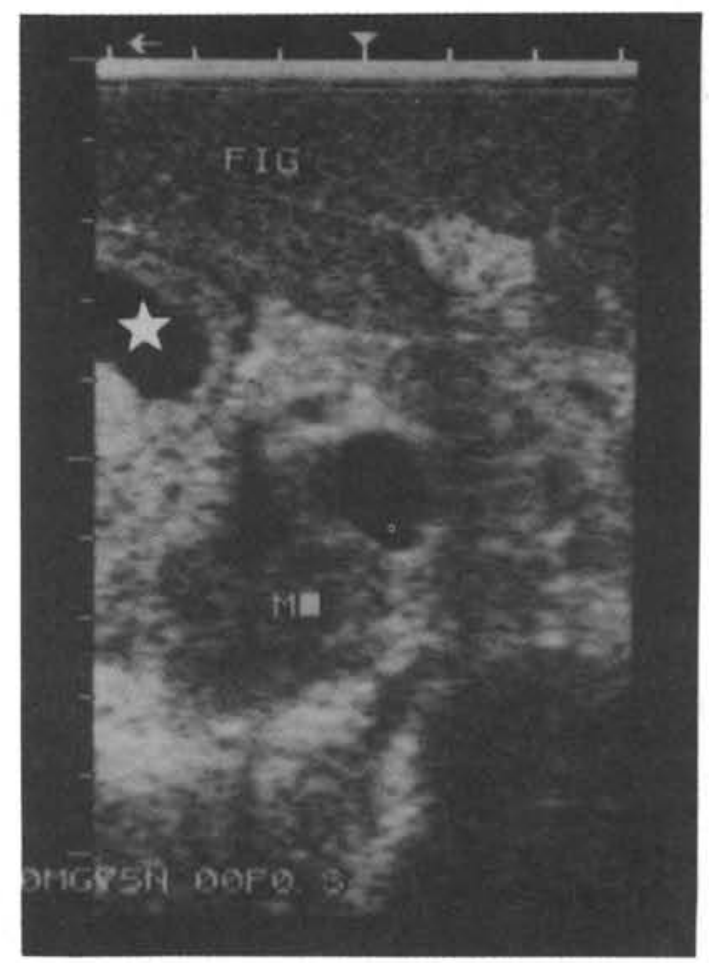

Figure 4 - Solid mass in head of pancreas. Duodenum (8).

Table 2

Comparison between pre and intraoperative findings. (Pancreas.)

\begin{tabular}{lll}
\hline Patient number & Preoperative US/CT & IOUS \\
\hline 1. & Normal pancreas & Same findings \\
2. & $\begin{array}{l}\text { Mass in pancreas head and } \\
\text { dilation of Wirsung duct } \\
\text { 3. }\end{array}$ & Normal pancreas. Dilation of Wirsung duct \\
4 & $\begin{array}{l}\text { Normal pancreas } \\
\text { Solid nodule in the transition between }\end{array}$ & $\begin{array}{l}\text { Same findings } \\
\text { Two solid hipoecogenic nodules in the same area }\end{array}$ \\
5. & Solid nodule in pancreatic body & Same findings \\
6. & Normal pancreas & Solid mass in the head of the pancreas \\
7. & Two solid nodules & Two hipoecogenic solid nodules and 1 cystic nodules \\
8. & Normal pancreas & Same findings \\
9. & Normal pancreas & Solid hipoecogenic nodule in the head of the pancreas \\
10. & Pancreatic nodule & Chronic pancreatitis, with no nodules \\
11. & Peripancreatic mass & Same findings \\
12. & Pancreatic tumor & Normal pancreas \\
\hline
\end{tabular}




\begin{tabular}{lc}
\hline \multicolumn{2}{c}{$\begin{array}{c}\text { Table 3 } \\
\text { Agreement between preoperative examinations } \\
\text { and IOUS (liver and bile duct.) }\end{array}$} \\
\hline Agreement & 24 cases $(61.5 \%)$ \\
Difference & $15 \operatorname{cases}(38.5 \%)$ \\
Total & $39 \operatorname{cases}(100 \%)$ \\
\hline
\end{tabular}

\section{PATIENTS AND METHODS}

Forty-two patients who underwent abdominal surgery with a tentative diagnosis of hepatobiliary and pancreatic disease between 1991 and 1994 at the Hospital das Clínicas, FMUSP, were studied. One patient underwent the operation twice with IOUS. The patients were 13 to 82 years-old (average 46.5 years). Twenty-one were female and 21 male. They were divided in two groups, according to the diagnosis of hepatobiliary or pancreatic disease. In 8 cases, both the hepatobiliary and pancreatic areas were examined. All patients underwent ultrasonography and/ or $\mathrm{CT}$ in the preoperative period.

All intraoperative examinations were carried out by the author, using portable equipment, model 500 (Aloka, Tokyo, Japan), with sterile linear 5.0 and $7.5 \mathrm{MHz}$ transducers. Recordings were taken with a video printer.

The examination was standardized by longitudinally and transversally scanning the organ under study. The contact between transducer and the organ to be examined was established by utilizing peritoneal fluid and sterile

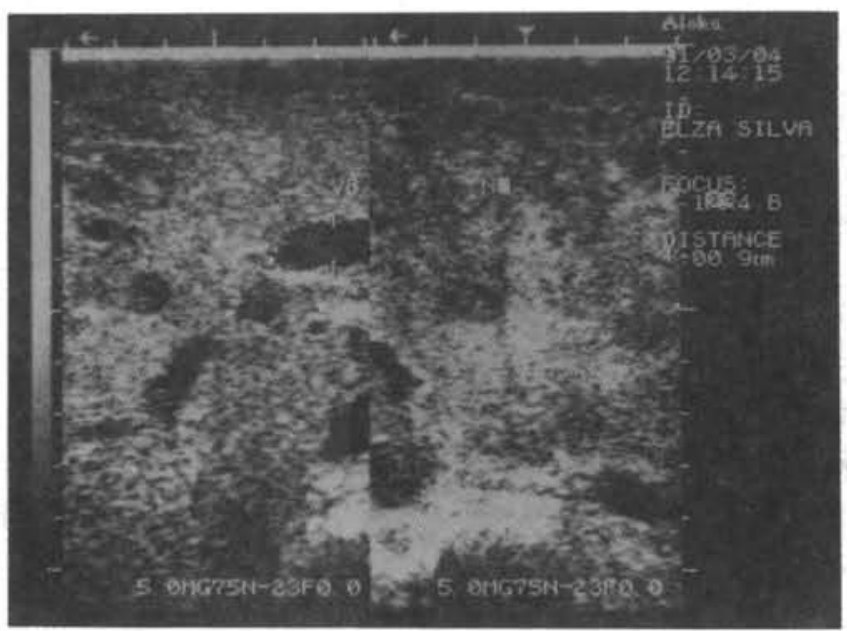

Hepatic metastases

Figure 5 -Multiple small hypoechogenic hepatic nodules.

\begin{tabular}{lc}
\hline \multicolumn{1}{c}{$\begin{array}{c}\text { Table } 4 \\
\text { Agreement between preoperative examinations } \\
\text { and IOUS. (Pancreas.) }\end{array}$} \\
\hline Agreement & 5 cases $(41.7 \%)$ \\
Difference & 7 cases $(58.3 \%)$ \\
Total & 12 cases $(100 \%)$ \\
\hline
\end{tabular}

Table 5

Agreement between findings of preoperative examinations and IOUS. (Liver, Bile duct and pancreas.)

\begin{tabular}{ll}
\hline Agreement & 29 cases $(56.8 \%)$ \\
Difference & 22 cases $(43.2 \%)$ \\
Total & 51 cases $(100 \%)$ \\
\hline
\end{tabular}

saline solution. In case of superficial lesions, a water-filled surgical glove was utilized for better focusing. In case of non-palpable or inaccessible lesions, a IOUS-guided puncture was performed.

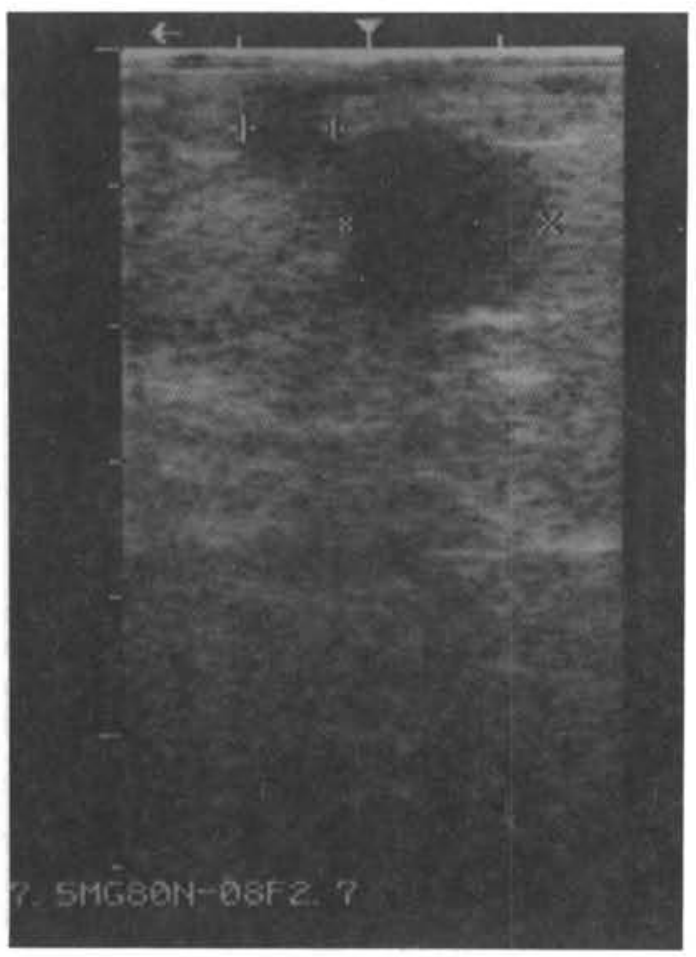

Insulinoma

Figure 6 - Two solid hypoechogenic nodules of 0.7 and $1.5 \mathrm{~cm}$ identified in pancreatic tail. 
Table 6

IOUS-guided procedures

\begin{tabular}{ll}
\hline Patient & Procedure \\
1. & Guidance for drainage of multiple bilobar hepatic abscesses. \\
2. & Guidance for drainage of residual abscess in right hepatic lobe (Segment VIII). \\
3. & Puncture/biopsy of solid area of mixed lesion of left hepatic lobe (Segment IV). \\
4. & Puncture/biopsy and alcoholization of hypoechogenic nodule in left hepatic lobe (Segment VII). \\
5. & Puncture/biopsy and alcoholization of hyperechogenic, non-palpable nodule in right hepatic lobe (Segment VI). \\
\hline
\end{tabular}

\section{RESULTS}

Thirty-nine examinations for the investigation of hepatobiliary disease were carried out. In this group of patients, the surgical indications were: primary hepatic tumors; hepatic abscesses; high and low obstructive jaundice; gall bladder tumors; searching for hepatic metastasis from gastric and colonic malignancies; and neuroendocrine tumors. In the 12 patients who underwent surgery for pancreatic disease, the main purpose of the examinations was to search for neuroendocrine tumors.

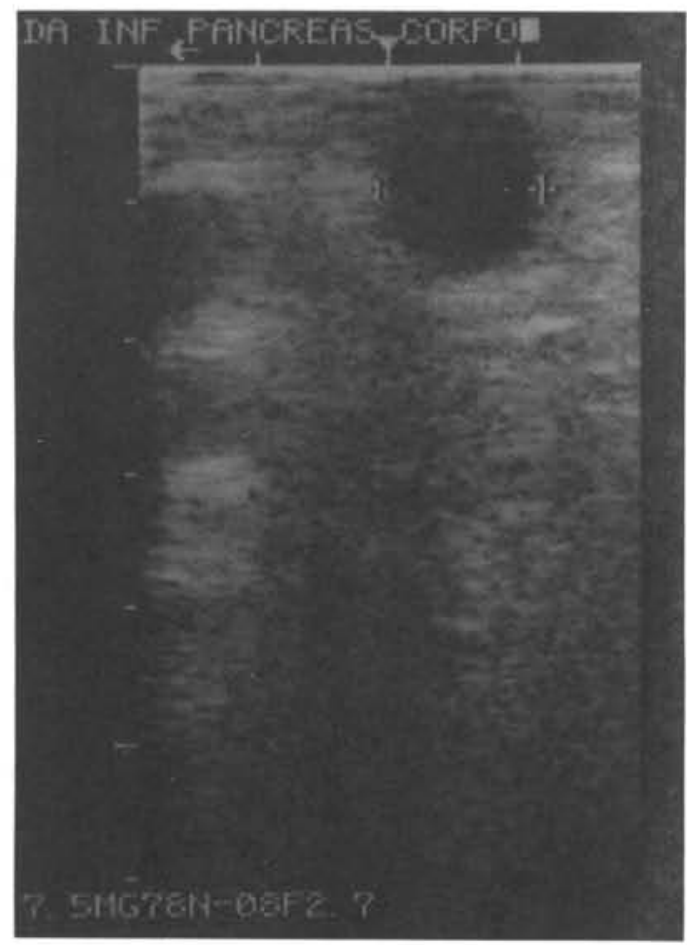

Figure $7-1.3 \mathrm{~cm}$ cyst in pancreatic body.

\section{A COMPARISON BETWEEN PREOPERATIVE EXAMINATIONS AND IOUS (Tables 1 and 2 )}

In 24 cases (61.5 percent) from the hepatobiliary group, there was an agreement between preoperative and intraoperative findings. In 15 cases ( 38.5 percent), the results from IOUS were different.

The most frequent divergencies in this group were related to the number of preoperative identified lesions. In six cases (16.7 percent), a larger number of lesions

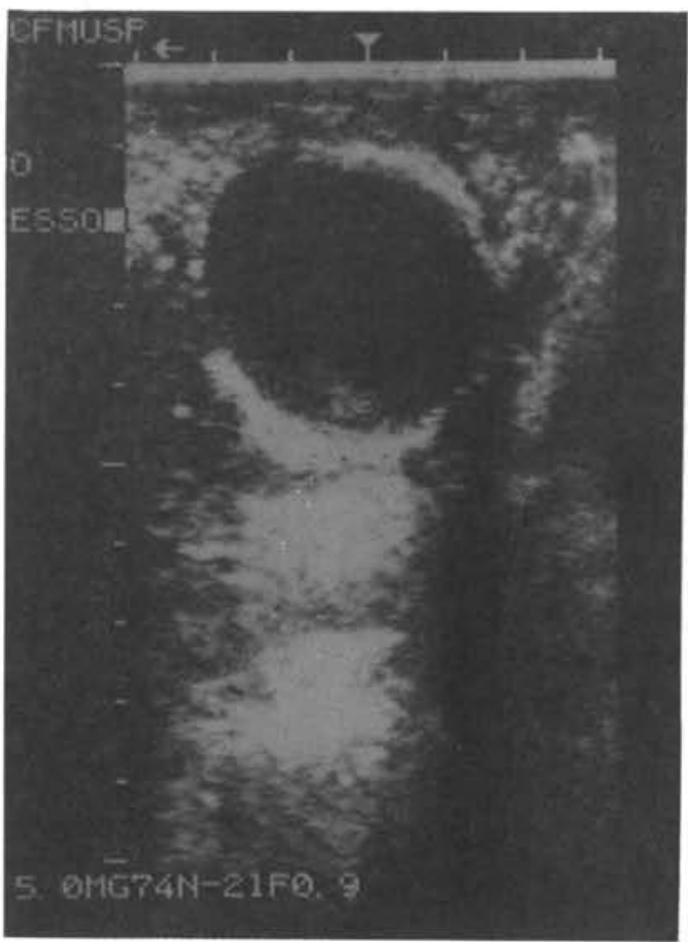

Hepatic abscesses

Figure 8 -Image of fluid content, with a thickened wall. 


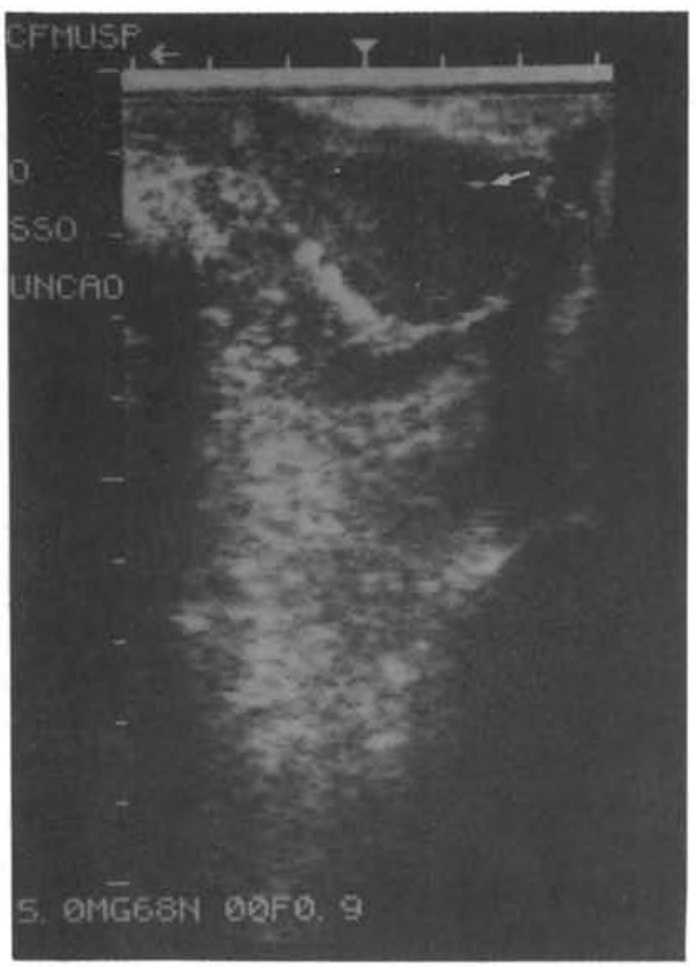

Figure 9 - After puncture, there was a reduction in the size of the abscess. Needle (arrow).

was detected by IOUS. The diameter of these lesions ranged from 0.4 to $1.5 \mathrm{~cm}$. Other alterations identified by IOUS, not discovered by preoperative findings, were related to the solid or cystic nature of lesions, size of lesions, hilar lymphadenopathy, and dilation of the intraheptaic bile duct.

In the group of patients who underwent pancreatic preoperative investigation, agreement between preoperative and intraoperative findings was observed in 5 cases ( 41.7 percent). In 7 cases ( 58.3 percent), IOUS showed different results. The detection of pancreatic nodules of 0.9 to $1.2 \mathrm{~cm}$ was the main contribution of the intraoperative study of the pancreas. Tables 3 and 4 give the results for both the agreement and differences between preoperative and intraoperative methods in the hepatobiliary and pancreatic groups. Table 5 summarizes the results of the two groups.

\section{IOUS-GUIDED SURGICAL PROCEDURES}

IOUS was used for guiding either punctures and biopsies in 5 cases ( 9.8 percent). The procedures were

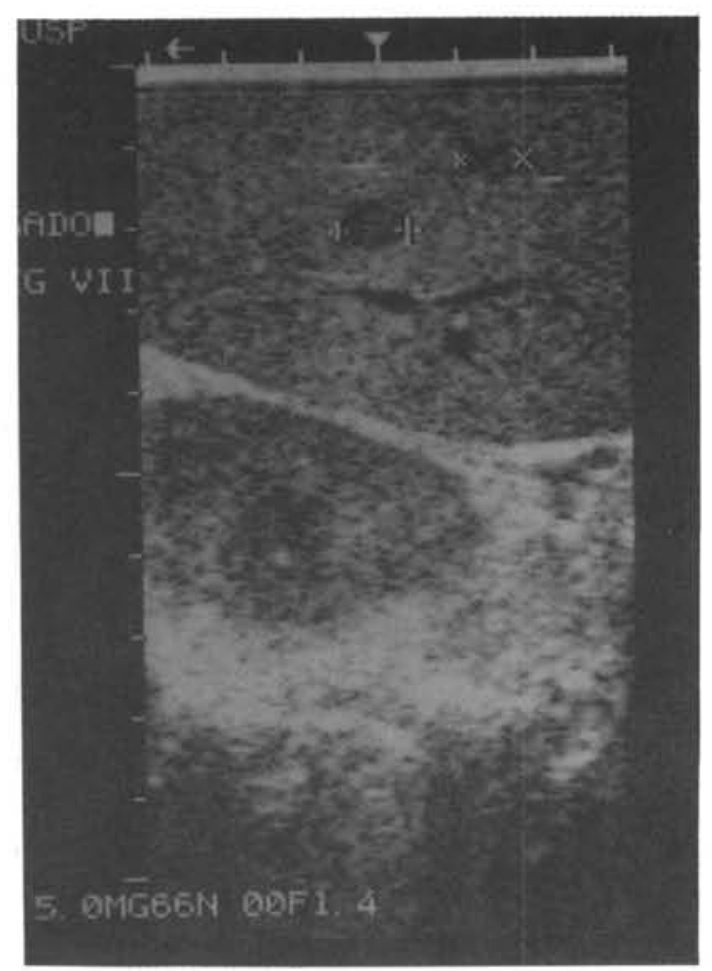

Hepatic metastases of carcinoma of the colon.

Figure 10 - Through IOUS another $0.8 \mathrm{~cm}$ solid, hypoechogenic nodule was found, next to the above mentioned.

punctures performed for guiding either biopsies or nodule alcoholization. Drainage of parenchimatous collections, inaccessible to the surgeon's vision and/or palpation, were also performed. Table 5 depicts such procedures.

\section{DISCUSSION}

IOUS has evolved greatly in the last 15 years. It used to be a complex method, with a limited span of indications, frequently associated with an increase in surgical time. The improvement in quality of ultrasonography equipment, with the development of transducers for this purpose, smaller and with greater resolution, has increased the importance of the method in digestive tract surgery. In many centers, it is routinely used in liver, pancreas and bile duct diagnostic exploration. ${ }^{16}$

The main indications for IOUS use are: 1) detecting small hepatic primary tumors or metastases; 2) precisely staging either primary liver tumors or hepatic metastases; 3) visualizing intrahepatic vascular anatomy, in order to make segmentomies feasible; 4) identifying bilio-pancreatic ductal structures and their contents; 5) searching for nodular 


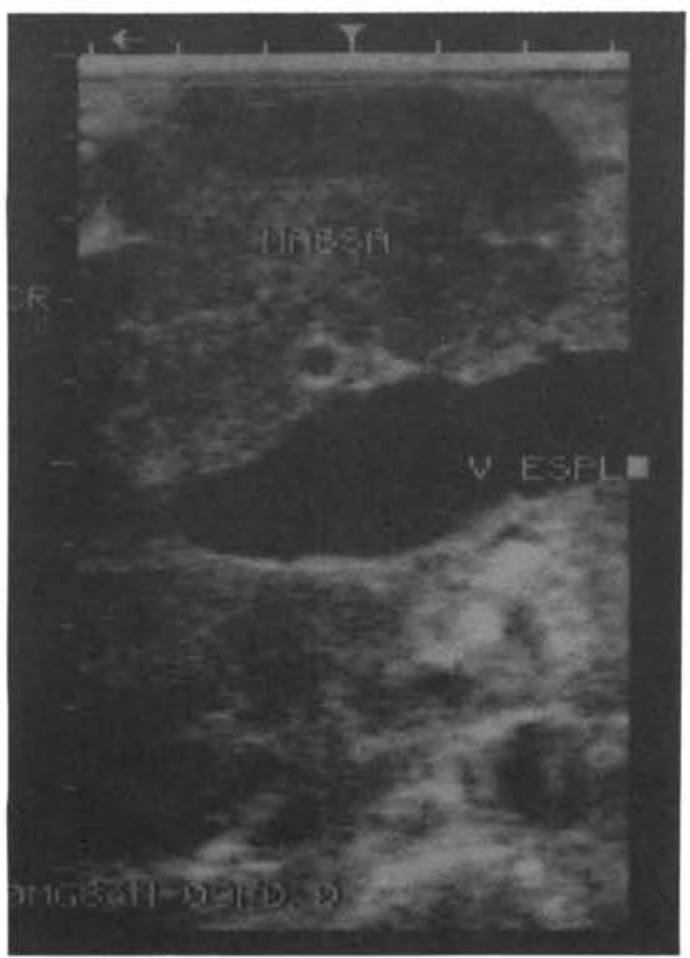

Lymphoma

Figure 11 - Ganglionar mass in hepatic hilus, compressing the portal system.

structures in cirrhotic livers; 6) establishing the diagnosis of pancreatic endocrine tumors; 7) as a guide for catheterizing vascular and ductal structures; 8) as a guide for localizing and puncturing both hepatic abscesses and pancreatic liquid collections; 9 ) as a guide for the puncture and biopsy of undiagnosed hepatic nodules; 10) in therapeutic puncturing (alcoholization and instillation of chemotherapheutic agents) of hepatic nodules. ${ }^{17}$

In the present series, the main purpose for IOUS was searching for metastatic hepatic nodules in patients with gastric, intestinal and pancreatic malignancies. The goal of the examinations was the intraoperative detection of unidentified non-palpable nodules.

The image-utilizing methods for routine liver examination are ultrasonography and CT. Nevertheless, these procedures cannot detect hepatic metastases, either single or multiple, particularly those that are small. The problems associated with the examination technique were artifacts, the patient's physical type, anatomic variations, allergy to contrast, and, in particular, the size of the lesions.

All these factors reduce the sensitivity of both of IOUS and CT. It is estimated that approximately 20 percent of metastases are preoperatively identified. IOUS

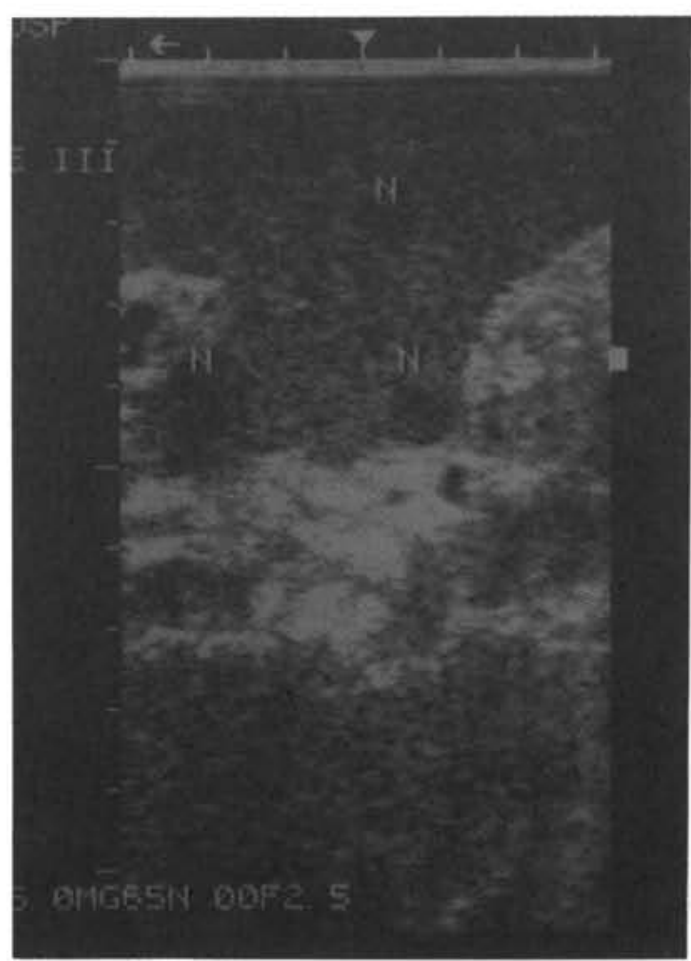

Cellular hepatocarcinoma

Figure 12 - The three small $(0.5 \mathrm{~cm})$ solid nodules in the left hepatic lobe were only identified by IOUS.

is useful principally in the detection of minute and deeply located lesions in the hepatic parenchima. The method can lead to a precise detection and location of lesions, as well as their spatial relationships with intrahepatic vascular structures. ${ }^{17-19}$ The high resolution of IOUS allows for the differentiation of lesions with benign features like cysts and hemangiomas, from metastaticlooking nodules, which are frequently hypoecogenic and display a target configuration. ${ }^{17.20}$

Two out of 39 cases in the hepatobiliary group had a diagnosis of chronic hepatic disease (cirrhosis). In both of them, intraoperative IOUS detected nodules previously not observed. Both patients had a US/CT diagnosed nodule in the right hepatic lobe. The discovery of left lobe tumoral involvement changed the surgical plan, which resulted in the avoidance of right hepatectomy. In its place, alcoholization of nodules was performed. These nodules, four in number, were less than $1.0 \mathrm{~cm}$ in diameter.

In chronic hepatic disease, the parenchimal heterogeneity has seen as an additional difficulty for preoperative detection of small nodules. For this reason, IOUS has been utilized in examining cirrhotic patients for nodules smaller than $5.0 \mathrm{~cm} .{ }^{9 \cdot}{ }^{21}$ The method has also 
proved to be useful in evaluating tumoral intravascular growth in the hepatic and portal veins. ${ }^{9.22}$

IOUS allows for the clear identification of portal branches and hepatic veins. Thus, the tridimensional nature of tumoral and vascular structures are easily recognized by the surgeon. Through this method, as well as guided puncture techniques, a new surgical procedure such as subsegmentectomy was developed.'. 23

Hepatic resections have become a more common procedure. However, most patients with cellular hepatocarcinoma have associated cirrhosis. In these patients, a wide resection is a risky procedure, due to the hepatic failure which could occurr. Thus, IOUS plays a important role in guiding more economic resections. Also benign lesions (like cavernous hemangiomas, adenomas and nodular focal hyperplasy) have been benefited by these segmental or subsegmental resections, leading to the avoidance of unnecessary lobectomies. IOUS is helpful in performing subsegmentectomies because it allows the visualization of intrahepatic vascular structures which have no anatomical expression on the hepatic surface.9. 14. 22-24

In the group of patients with bile disease, cases of bile duct dilation, malignancies, and lithiasis have been

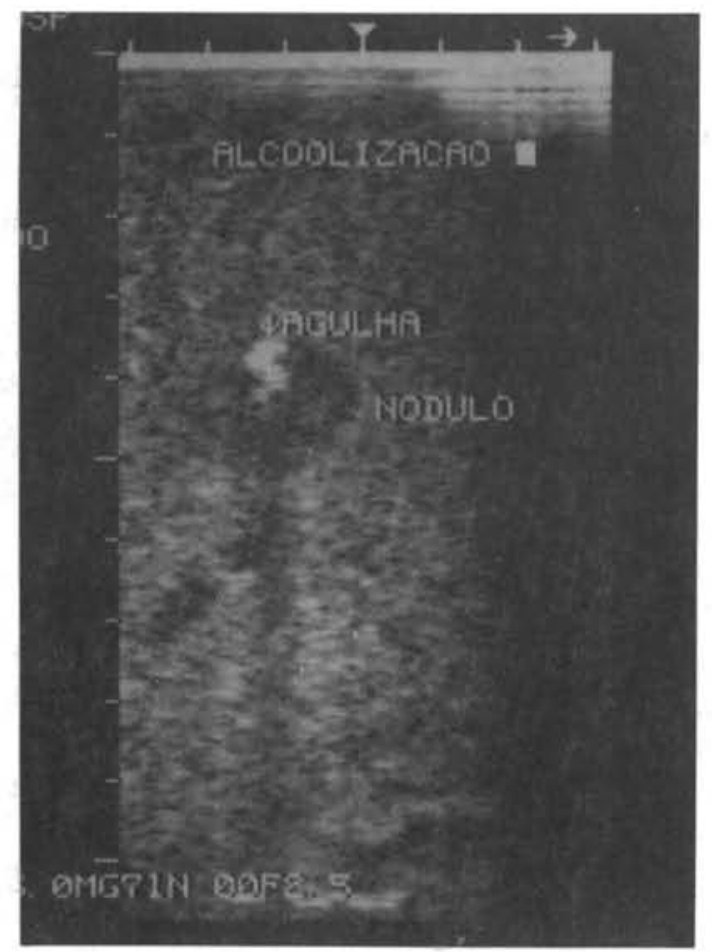

Figure 13 - Hyperrefringent image in the center of the lesion corresponds to needle tip. evaluated. The gallbladder has usually been adequately studied through preoperative ultrasonography. ${ }^{6.25}$

In recent years, IOUS has been used to explore either intrahepatic and intrahepatic biliary ducts. Recent studies have suggested that intraoperative cholangiograpy be replaced by IOUS. Cholangiography is a technique used to detect common duct calculi with sensitivity and specificity of approximately 90 to 95 percent. Nevertheless, it has some technical limitations and interpretation problems due to bubble formation. It also has the disadvantage of prolonging surgical time, because of the procedure itself and the additional time needed for the development of the film. On the other hand, IOUS is a non-invasive, simple and fast method. The results in the detection of biliary calculi have been similar for both methods. ${ }^{26,27}$

In the case of cholangiocarcinoma seen in this series, IOUS was useful in staging and establishing anatomical relationships, similarly to what has been previously discussed for hepatic masses.

In this series, there was an agreement between the preoperative examinations and preoperative IOUS in 61.5 percent of the cases. In the cases of liver and bile duct diseases, a 38.5 percent difference was found. Bismuth et

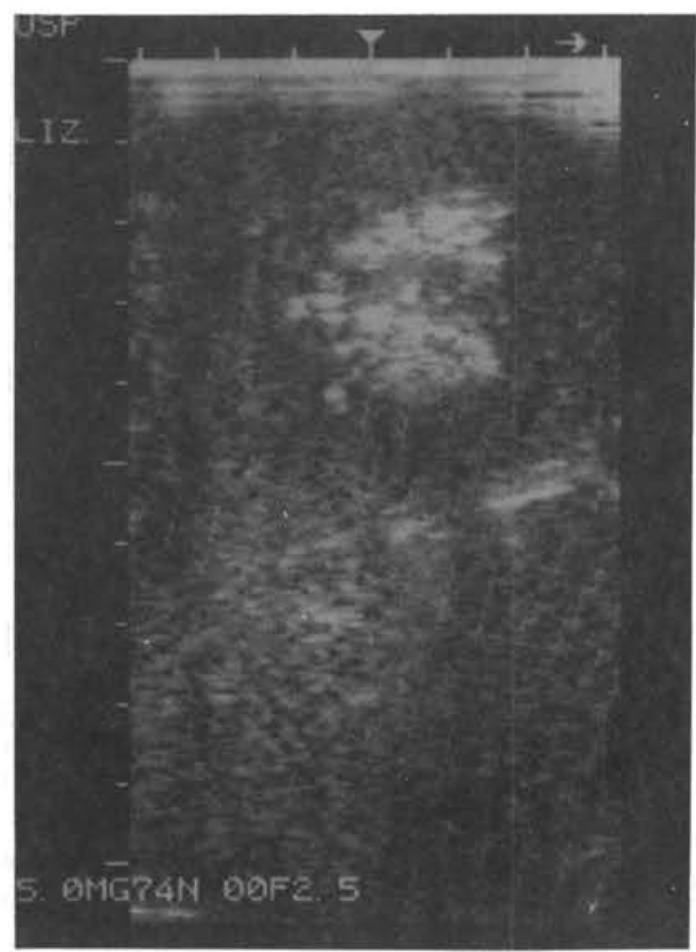

Figure 14 - At the moment of alcoholization, the nodule becomes hyperechogenic. 
al. $^{28}$ reported a 67 percent agreement and a 33 percent difference between IOUS and other image-utilizing preoperative examinations. Clarke et al. ${ }^{29}$ found up to 35 percent additional lesions with IOUS, as compared to other preoperative methods.

In the group of patients investigated for suspected pancreatic disease, the main indication for IOUS was the search for endocrine tumors. In the eight cases with suspected endocrine tumors, IOUS supplied additional information in three, as compared to other preoperative examinations. In two of these cases, a solid nodule was identified through the method. In the other, a preoperatively-diagnosed solid nodule, was found to be a cyst.

In the four cases of non-endocrine pancreatic disease, two were suspected of being tumorous. In both, IOUS showed a normal pancreas. In another case, in which the preoperative examinations results were normal, IOUS showed a mass in the head of pancreas.

Various authors have emphasized the importance of IOUS as a routine diagnostic procedure for the identification of endocrine tumors. Due to the small dimensions of theses nodules, the preoperative diagnosis is usually difficult or inconclusive. Thus, the intraoperative location of tumor, by palpation and IOUS, is very important. The contribution of IOUS is particularly important in the study of multiple endocrine tumors. The complementary character of conventional sonography, and IOUS plus palpation, gives the surgeon increased safety in the resection of small nodules..$^{10.310 .31}$

In the present study, IOUS provided additional data, as compared to other preoperative examinations (35.5 percent of the cases of neuroendocrine tumors). According to literature, the sensitivity of preoperative US/CT in detecting neuroendocrine tumors is fairly variable, ranging from 30 to 80 percent. ${ }^{20}$ The sensitivity of IOUS is 90 percent, thus surpassing the other preoperative methods. ${ }^{12,20,31}$

As for the other indications for IOUS, the findings of this study agree with those from literature, in terms of its use for the detection of pancreatic anatomic alterations, identification of the Wirsung duct, evaluation of texture, and the observation of peripancreatic vascular structures. The method is useful for the diagnosis of tumors and chronic pancreatitis. Its accuracy surpasses that seen in other preoperative examinations. ${ }^{6.7}$ Siegel et al. ${ }^{7}$ reported that IOUS was helpful in 69 percent of surgery cases for pancreatitis and in 69 percent of surgical procedures for tumors.

Interventional ultrasonography has been very useful in guiding several percutaneous techniques. Its main indications are related to procedures in which needles and catheters are necessary, such as in the drainage of abscesses, aspiration of cysts, injection of alcohol and chemotherapeutic agents, and biopsy procedures. These operative procedures can also be done with IOUS.' ${ }^{10 .} 2 \mathrm{x}$

In the present series, intraoperative IOUS was used in five cases, guiding biopsies and alcoholizations of hepatic nodules, and drainage of hepatic abscesses. In these cases, the purpose was performing diagnostic and therapeutic punctures on inflammatory and neoplasic hepatic lesions that, due to their localization, were not readily accessible by visualization or palpation. A decrease in operative time and an increase in surgical safety were additional advantages.

Although the present study deals only with hepatic operative procedures, other authors have mentioned the use of IOUS in pancreatic operations, such as the internal drainage of pseudocysts and the catheterization of a dilated Wirsung duct. Intraoperative US has been also useful in bile duct surgery, in catheterizing and draining bile ducts, and in performing puncture/biopsy of tumors. ${ }^{32}$

IOUS is an additional procedure in surgical operations, which leads to an increase in operative time. However, by allowing a rapid identification of small lesions, a more precise staging of tumors, guiding resections that would otherwise be performed blindly, and by making associated surgical procedures feasible, the end result is actually a shortening of overall operative time.

The appearance of contrast dyes in association with IOUS, as proposed by Takada et al., ${ }^{33}$ opens good perspectives for locating even smaller tumors. This contributes to a better prognosis. The injection of $\mathrm{CO}_{2}$ into the hepatic artery was not associated with harmful side effects.

The new IOUS apparatus, equipped with a color doppler, had brought an advancement to the technique. It allows the rapid identification of the arterial and venous vasculature, which makes possible the differentiation between blood vessels and other channel-like structures. The improved recognition of the hepatobiliary and pancreatic anatomy has made surgical dissections in these areas easier.

Laparoscopic surgery represents a major advance in surgical technique in the last decade. Specially designed transducers which allow monitoring these procedures had been developed. Some of them are still in the early phases of utilization. This represents a major contribution of IOUS, as more safety and an improved visualization in laparoscopic surgery are provided. ${ }^{27}$ In our opinion, IOUS will soon become a routine procedure associated with these techniques. 


\section{CONCLUSIONS}

1. IOUS plays an important role in detecting small hepatic nodules, either primary or metastatic.

2. IOUS is an important technique in precisely identifying hepatic lesions and their anatomical vascular relationships.

3. IOUS should be routinely used in cirrhotic patients with hepatic tumors, for the purpose of detecting nodules difficult to diagnose preoperatively and difficult for the surgeon to see because of the heterogeneity of the hepatic parenchima.

4. IOUS was found to be an important procedure in the detection of minute pancreatic tumors.

5. IOUS has better sensitivity than preoperative US/ CT in detecting hepatobiliary and pancreatic alterations.

6. IOUS has been useful in association with intraoperative procedures, such as biopsies, the alcoholization of nodules, and the drainage of abscesses.

\section{RESUMO}

É discutida a utilizaçāo da ultra-sonografia intra-operatória na avaliaçāo do fígado, vias biliares e pâncreas e comparados os resultados com os de ultra-som e tomografia computadorizada pré-operatórios. Foram estudados 42 pacientes submetidos a cirurgia abdominal por suspeita de doença hepatobiliar e/ou pancreática. $O$ estudo intra-operatório foi realizado com aparelho portátil (Aloka 500, Japão), utilizando-se transdutores lineares estéreis de $5.0 \mathrm{MHz}$ e $7.5 \mathrm{MHz}$. As principais indicaçōes da ultra-sonografia intra-operatória foram: avaliar massas hepáticas primárias, abscessos hepáticos, icterícia obstrutiva, pesquisa de metástases hepáticas e pesquisa de tumor neuroendócrino. Em 15 casos (38,5\%) do grupo hepatobiliar e em sete casos $(58,3 \%)$ do grupo pancreático houve divergência entre os achados pré e intra-operatórios. A principal divergência foi quanto ao número e dimensāo das lesōes hepáticas e pancreáticas. A ultra-sonografia intra-operatória permitiu estabelecer relaçōes anatômicas da lesão com estruturas vasculares. Este método de exame também foi utilizado para guiar procedimentos intervencionistas como biópsia e alcoolização de nódulos e drenagem de abscessos. Conclui-se que a ultra-sonografia intraoperatória tem papel importante na detecção de pequenos nódulos hepáticos e pancreáticos, no estabelecimento de relaçōes anatômicas de lesōes com estruturas vasculares e na realização de procedimentos intervencionistas.

\section{REFERENCES}

1. Grode ML, Komaiko MS. The role of intraoperative ultrasound in neurosurgery. Neurosurgery 1983;12(6):6248.

2. Schlegel JU, Diggdon P, Cuellar J. The use od ultrasound for localizing renal calculi. J Urol 1961;86(4):367-9.

3. Hayashi S, Wagai T, Miyazawar R et al. Ultrasonic diagnosis of breast tumor and cholelithiasis. West J Surg Obstet Gynecol 1962:34-40.

4. Knight PR, Newel JA. Operative use of ultrasonics in cholelithiasis. Lancet 1963:1023-5.

5. Eiseman B, Greenlaw RH, Gallagher JQ. Localization of common duct stones by ultrasound. Arch Surg 1965;91:195-9.

6. Deixonne B, Lopez FM. Operative ultrasonography during hepatobiliary and pancreatic surgery. Berlin, Springer, 1988.
7. Siegel B, Machi J, Ramos JR, Duarte B, Donahue PE. The role of imaging ultrasound during pancreatic surgery. Ann Surg 1984;200(4):486-93.

8. Lane RJ, Coupland GA. Ultrasonic indications to explore the common bile duct. Surgery 1982;91(3):268-74.

9. Makuuchi M, Hasegawa H, Yamazaki S. Ultrasonically guided subsegmentectomy. Surg Gynecol Obstet 1985;161:346-50.

10. Paranagua Vezozzo DC, Rocha DC, Cerri GG. Fígado. In: Cerri GG, Rocha DC. Ultra-sonografia abdominal: convencional, doppler, técnicas endoscópicas, pediatria, intervenção. São Paulo, Sarvier, 1993. p.61-90.

11. Schlinkert RT, Burns B, Argueta R, Whitaker MD, Danielson KS, Trejos FA. Insulinoma in a patient with annular pancreas. Mayo Clin Proc 1990;65:518-20.

12. Ferreyra NP, Athaide ACM, Paranagua Vezozzo DC, Rocha DC, Cerri GG. Pâncreas. In: Cerri GG, Rocha DC. 
Ultrasonografia abdominal: convencional, doppler, técnicas endoscópicas, pediatria, intervenção. São Paulo, Sarvier, 1993. p. 143-68.

13. Rifkin MD, Rosato FE, Branch HM, Foster J, Yang SL, Batbot DJ, Marks GJ. Intraoperative ultrasound of the liver. An important adjunctive tool for decision making in the operating room. Ann Surg 1987;205(5):466-72.

14. Salminen PM, Höcherstedt K, Edgren J, Scheinin TM, Tierala E. Intraoperative ultrasound as an aid to surgical strategy in liver tumor. Acta Chir Scand 1990;156:329-32.

15. Gozzetti G, Angelini L. The use of intraoperative ultrasonography in hepatic surgery. In: Intraoperative and endoscopic ultrasonography. New York, Churchill Livingstone, 1987. p.83-103.

16. Castaing D, Emond J, Kunstlinger F, Bismuth H. Utility of operative ultrasound in the surgical management of liver tumors. Ann Surg 1986;204(5):600-5.

17. Machi J, Isomoto H, Yamashita Y, Kurohiji T, Shirouzu K, Kakegawa T. Intraoperative ultrasonography in screening for liver metastases from colorectal cancer: comparative accuracy with traditional procedures. Surgery 1987;101(6):676-84.

18. Boldrini G, Gaetano AM, Giovannini I, Castagneto M, Colagrande $\mathrm{C}$, Castiglioni $\mathrm{G}$. The systematic use of operative ultrasound for detection of liver metastases during colorectal surgery. World J Surg 1987;11(5):622-7.

19. Russo A, Sparacino G, Plaja S, Cajozzo M, La Rosa C, Demma I, Bazan P. Role of intraoperative ultrasound in the screening of liver metastases from colorectal carcinoma: initial experiences. J Surg Oncol 1989;42:249-55.

20. Paranagua Vezozzo DC, Cerri GG, Siqueira SAC, Caudelori I, Alves VAF, Magalhães A. Contribuição da ultra-sonografia no diagnóstico dos tumores endócrinos do pâncreas. Radiol Bras 1990;23:95-101.

21. Sheu JC, Lee CS, Sung JL, Chen DS, Yang PM, Lin TY. Intraoperative hepatic ultrasonography. Surgery 1985;97(1):97-103.

22. Nagasue N, Suehiro S, Yukaya H. Intraoperative ultrasonography in the surgical treatment of hepatic tumors. Acta Chir Scand 1984;150:311-6.

23. Makuuchi M, Hasegawa H, Yamazaki S, Takayasu K, Moriyama N. The use of operative ultrasound as an aid to live resection in patients with hepatocellular carcinoma. World J Surg 1987;1 I(5):615-2I.

24. Parker GA, Lawrence Jr W, Horsley III S, Neifeld JP, Cook D, Walsh J, Brewer W, Koretz MJ. Intraoperative ultrasound of the liver affects operative decision making. Ann Surg 1989;209(5):569-76.

25. Oliveira LM, Munhoz S. Rocha DC, Cerri GG. Vesícula biliar. In: Cerri GG, Rocha DC. Ultra-sonografia abdominal: convencional, doppler, técnicas endoscópicas, pediatria, intervenção. São Paulo, Sarvier, 1993. p.91-116.

26. Buckley AR, Scudamore CH, Becker CD, Cooperberg PL. Intraoperative imaging of the biliary tree. Sonography vs. operative cholangiography. J Ultrasound Med 1987;6:58995.

27. Mosnier H, Audy JCR, Boche O, Guivarc'h M. Intraoperative sonography during cholecystectomy for gallstones. Surg Gynecol Obstet. 1992;174:469-73.

28. Bismuth H, Castaing D, Garden J. The use of operative ultrasound in surgery of primary liver tumors. World J Surg 1987;11(5):610-4.

29. Clarke MP, Kane RA, Steele Jr G, Hamilton ES, Ravikumar TS, Onik G, Clouse ME. Prospective comparison of preoperative imaging and intraoperative ultrasonography in the detection of liver tumors. Surgery 1989;106(5):849-55.

30. Cromack DT, Norton JA, Sigel B, Shawker TH, Doppman JL, Maton PN, Jensen RT. The use of high-resolution intraoperative ultrasound to localize gastrinomas: an initial report of a prospective study. World J Surg 1987;11(5):648-53.

31. Norton JA, Cromack DT, Shawker TH, Doppman JL, Comi R, Gorden P, Maton PN, Gardner JD, Jensen RT. Intraoperative ultrasonography localization of islet cell tumors. A prospective comparison to palpation. Ann Surg 1988;207(2):160-8.

32. Machi J, Sigel B, Kurohiji T, Zaren HA, Sariego J. Operative ultrasound guidance for various surgical procedures. Ultrasound Med Biol 1990;16(1):37-42.

33. Takada T, Yasuda H, Uchiyama K, Hasegawa H, Shikata J. Contrast-enhanced intraoperative ultrasonography of small hepatocellular carcinomas. Surgery 1990;107(5)528-32. 